\title{
Developing Cognitive Assessment Objectives in Language Syllabus Design
}

\author{
Stephen McNamara ${ }^{1}$ \\ ${ }^{1}$ Kwansei Gakuin University.
}

ARTICLE INFO

Keywords:

CLIL, Cognitive

Domain, Cognitive

Taxonomy, Syllabus

Design, Assessment

Design, Japan

\begin{abstract}
As research begins to push syllabus developers more firmly towards a Content and Language Integrated Learning (CLIL) based approach to second language acquisition, content-focused courses and their development are a growing trend in Japanese tertiary education contexts. Actions by the Ministry of Education (MEXT) have reinforced this focus, and have created a need for syllabus designers to adapt their practices to incorporate content learning as a vehicle for driving second language acquisition. In turn, cognitive development, seen in CLIL theory as having a synergistic effect on linguistic and content mastery, is an area of interest for syllabus designers in Japan, especially as widely publicised context-specific teaching materials are still in earlier stages of dissemination.

This study looks in detail at the relationship between cognitive domain taxonomic indicators and how they interact with linguistic development, in a specific Japanese tertiary syllabus. This study aims to improve the efficacy of this syllabus and its assessment in the following ways:

1. By distinguishing students' perceptions of difficulty in answering quiz questions based on Bloom's and Anderson and Krathwohl's taxonomies of the cognitive domain (1956, 2001), using a 12 item questionnaire;

2. By comparing these perceptions of difficulty to the difficulty levels implied by the hierarchical nature of the taxonomies;

3. To offer conclusions and suggestions made from the implications of one and two, in order to better develop course teaching and assessment for both language acquisition and content mastery
\end{abstract}

\section{Introduction}

As research begins to push syllabus developers more firmly towards a Content and Language Integrated (CLIL) based approach to second language acquisition, content-focused courses and their development are becoming a growing concern in Japanese tertiary education contexts. This differs from the view of practice held by many in the teaching establishment in 
Japan, where a prescriptive approach, reliant on grammar-translation methodology, has been common for decades (Saito, 2012. Cook, 2010), although this is changing. Second language learning has been seen by many as a skill separated from content, that is, taught and learnt in a partial vacuum, with less emphasis on how the language relates to the context of its use, and more upon the discrete development of linguistic skill. To generalise Japanese contexts, where the second language is primarily English, the application of a second language is often limited to its assessment, particularly on lexical and grammatical knowledge, disregarding the possibilities for application to interdisciplinary study. That is to say, often, language is learnt for the purpose of passing exams. However, in recent years, actions lead by MEXT or the Mombushō, the Ministry of Education, Culture, Sports and Technology of Japan, amongst others, has seen the promotion of English as being an evermore important national skill-set, especially considering the looming Tokyo Olympics and its expected tourist boom, not to mention the perceived efficacy of English for international exchange, economic development and access to research (MEXT, 2014). Due to this, there has been increased financial and infrastructural support for nationally developing English as a second language, and although these changes will mostly affect an increase in the amount of time that learners spend in classrooms, the focus on testing as the primary aims of learning is only nominally abating (MEXT, 2014). At the tertiary level, the Mombusho has designated a number of universities as "Global 30" institutions, and this shows an admirable national commitment to second language acquisition development, including a welcomed step toward a more context based approach (MEXT, ND). Further, the shift can be viewed in the rapidly growing international education sector, with 700 International Baccalaureate schools operating in the Asia Pacific (IBO.org., 2016). In fact, the first Japanese public school to utilize an IB curriculum, Suito Kokusai, in Osaka, is being slated to open, with authorization pending in perhaps the next five years (Osaka City, ND). This is mentioned as IBO curricula have an integrated approach to disciplines, extending to language study, a pertinent facet of this article.

Considering the general shift in thinking regards second language acquisition as mentioned above, Kwansei Gakuin University has included general education subjects in their EAP curriculum. The following study will focus on one such syllabus, Introduction to Western Art History, which has been developed following CLIL theories outlined by Coyle, Hood, and Marsh, D. (2010), amongst others. This syllabus employs adapted, updated, versions of Bloom's ubiquitous 1956 Taxonomy of the Cognitive Domain to inform difficulty and thematic sequencing.

This study aimed to improve the efficacy of syllabus design and assessment in this course in the following ways:

1. By distinguishing students' perceptions of difficulty in answering quiz questions based on Bloom's and Anderson and Krathwohl's taxonomies of the cognitive domain $(1956,2001)$;

2. By comparing these perceptions of difficulty to the difficulty levels implied by the hierarchical nature of the taxonomies;

3. To offer conclusions and suggestions made from the implications of one and two, in order to better develop course teaching and assessment 


\section{Context}

\section{The English Communication Programme}

Kwansei Gakuin University is located near Kobe in Western Japan. It is a large, private educational organization, with about 11 campuses in the Kansai region, offering courses from kindergarten to post graduate level. This study was undertaken at the School of Policy Studies, in their English Communication Programme. The EC programme is a compulsory two-year programme of four lessons per week. There are around 1200 students in the programme, mostly aged between 18 and 21, the majority from a Japanese speaking background. Students have, in general, completed at least 6 years of compulsory English education in the Japanese system, including the features mentioned above. This generalization is pertinent to how the syllabus in question was conceived as it relies upon the argument that students have studied English using largely homogenous pedagogy, and have similar educational backgrounds. There are however, disparities in student experiences and abilities within the EC programme, although students are for the most part testing within the 350's to 480's on the old version of the TOEFL PBT (the scoring system for TOEFL was updated in 2017, but the results for the current cohort have not been released yet). Due to the disparities in TOEFL scores, and aside from the necessities implied by the homogeneity of student backgrounds, the EC programme is graded into six levels, with two entry points. The TOEFL scores are used to place students at entry, as well as grade them into blocks.

With large cohorts and the many moving parts (a staff of around 50 at last count), lessons are strictly coordinated, and full time staff members write in-house student textbooks and lesson plans, and then manage their application.

In part due to the homogeneity of the cohorts, the mainstream EC programme has a 4 skills approach, something students are familiar with from their prior education in English. The mainstream EC programme aims to increase these skills, as an extension of high school and junior high attainment, and although thematically some content becomes more topical, the pedagogy of a discreet 4 skills approach largely remains intact. The primary goals of the programme are linguistic, and could be said to mirror the Japanese second language acquisition pedagogy. Content is included only where it can be used to drive language acquisition, and cognitive engagement with content is not an objective of this part of the programme. This has the benefit of giving students some cognitive breathing room as they advance in their learning, as the methods for acquisition may be almost second nature to them in this stage of their language learning careers. Additionally, there is literature that justifies this type of second language acquisition, although these are at times disputed by CLIL theorists and other modes of thought (Coyle et.al., 2010). This is not to say that the programme in question ignores the justifications and trends of CLIL mentioned in the introduction.

\section{Specific context: Special Topics Courses}

Aside from the mainstream components of the EC programme, second year students are offered "Special Topics" courses (ST). These are taught in one 90-minute lesson per week, and replace the more traditional linguistic instruction. There are about 400 students in this cohort. The ST lessons are more flexible in how they can be taught and developed than mainstream syllabi: 
they are explicitly content based, with the linguistic goals recycled or mirrored from other EC courses. The content is at the discretion of the teacher-developer, and require a textbook to be written in-house. Although the mainstream EC programme is well established in terms of pedagogy and development, the ST courses are still at an early phase of development. This gives the developers an opportunity to experiment with some CLIL ideas, but also necessitates careful monitoring of how well the ST syllabi are performing.

\section{Pedagogy}

The relative freedom in scope for syllabus development offered by the content-based classes affords an interesting chance for designers to begin to incorporate some CLIL approaches. This, coupled with the adjacent syllabi in which students complete the mainstream programme can give the designer a solid contextual base in which to operate. Due to this, the subject matter of art history was chosen for its adaptability in terms of allowing opportunities for both linguistic and content instruction. The syllabus is a 14-week semester, with roughly every two weeks representing a stratum of the taxonomy. Each week has a different thematic focus, a chronologically ordered representation of modern Western art history. The design of the syllabus is discussed in greater detail in McNamara, (2016).

Goal 1 of the Art History syllabus has these objectives:

Fig 1. Goals and Objectives

\section{Goal 1. Engage with art using appropriate language.}

Objective 1A. Use appropriate language to make observations about art.

- Observe locations using prepositions: The $\mathrm{X}$ is above the $\mathrm{Y}$

- Use lists of adjectives: $\mathrm{X}$ is a light, airy colour

- Describe order: X precedes Y

Objective 1B. Use appropriate language to discuss relationships between artworks, their makers and their contexts.

- Use comparatives: $\mathrm{X}$ is more vivid than $\mathrm{Y}$

- Describe differences: both/neither have

- Show influences: $\mathrm{X}$ is inspired by $\mathrm{Y}$

Objective 1C. Use appropriate language to make inferences and speculations.

- Use hedging phrases: We can guess that..

- Express likelihood: It is probable that..

- Express causality: Due to $\mathrm{X}, \mathrm{Y}$ is $\mathrm{Z}$.

Objective 1D. Use appropriate language to evaluate art.

- Prioritizing: $\mathrm{X}$ is more important than $\mathrm{Y}$

- Justifying: I believe this because..

- Assessing: $\mathrm{X}$ is successful because.. 
These objectives contain the functions from the cognitive domain, specifically drawn from Anderson and Krathwohl's 2001 version of Bloom's 1956 Taxonomy. Their sub-objectives show how and what language can be applied to each skill. Below, in figure 2, the cognitive domain thinking skills can be observed in the left hand column. These relate to the syllabus objectives, which follow a hierarchy of lower-order to higher-order thinking skills (LOTS and HOTS). The right column lists verbs commonly applied to these orders.

For example, at the lower level, the skills of "Knowledge" and "Comprehension" have been addressed in figure 1 objective 1A, "Making Observations". Indeed, some of the verbs in the right-most column of figure two are explicitly used in this objective, along with examples of how they are to be linguistically expressed.

Objective 1B covers "Application" and "Analysis", skills that (theoretically) are very difficult to apply without taking the earlier steps. Not mentioned in these objectives was the attempt at using biographies as well as readings that focused on cultural and political aspects to enable students to attempt comparisons between artists and their works.

Objectives 1C and 1D are fairly straightforward in their relationship to the taxonomy, and represent the higher order skills.

The hierarchical nature of Bloom's taxonomy would suggest that each objective is increasingly difficult. As such, the order of the objectives mirrors the sequencing of the syllabus. The sequencing of difficulty is also visible on a micro-level, with quizzes and other assessments employing a range of input designed to assess student abilities in each stratum.

It should be noted that although these attempts were made at aligning the syllabus with a taxonomic underpinning, the designer was at times bound by the imperatives of the curriculum and context, and hence at some points there was a feeling of "shoehorning" the subsets of the taxonomy to fit the objectives and vice versa. 
Figure 2. Bloom's cognitive domain. (Adapted from Bloom, 1956; McNamara 2018)

\section{Bloom's Cognitive Domain}

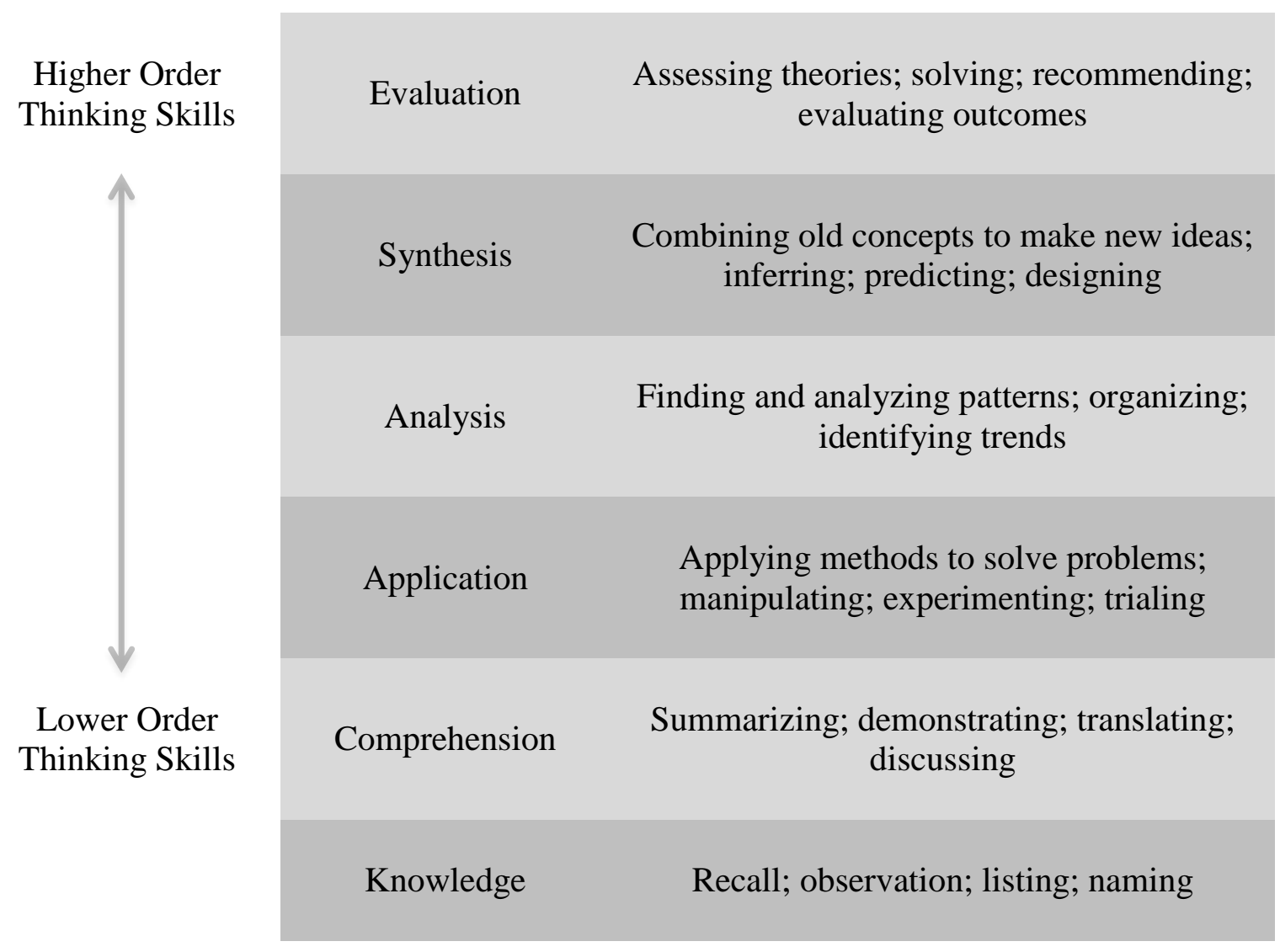

Further, Anderson and Krathwohl's revision of the Bloom's taxonomy was referenced when creating the questionnaire and its related quizzes (Anderson and Krathwohl, 2001). This revised taxonomy was employed as the cognitive descriptors have been reworded to be verbs, making the writing of quiz items more practicable. The verb descriptors make explicit appearances in the questionnaire and quizzes. Note, Anderson and Krathwohl (basically) switched evaluation and synthesis in their version, although their function remains very similar, but the syllabus in this case follows the original. Another pertinent difference is that the Anderson Krathwohl version gives more comprehensive information on how the taxonomy acts upon different types and levels of knowledge, allowing designers to better equipped for dealing with the cognitive aspect of planning assessments or otherwise (Wilson, 2001). The verb descriptors and the functions they imply were taught thorough the ST syllabus, although much of the specific meta-language was excluded to allow students to process the instruction more efficiently. Below, in figure 3 , the 
revised taxonomy can be compared to the original, including some excerpts of the descriptive additions.

Fig 3. Comparison of Bloom's 1956 taxonomy with Anderson and Krathwohl's 2001 revision. (Adapted from Wilson, 2013)

\begin{tabular}{|l|l|}
\hline Bloom's 1956 & Anderson and Krathwohl 2001 \\
\hline Evaluation & $\begin{array}{l}\text { Creating } \\
\text { "Putting elements together to form a coherent or functional } \\
\text { whole; reorganizing elements into a new pattern or structure" } \\
\text { Synthesis }\end{array}$ \\
$\begin{array}{l}\text { Evaluating } \\
\text { "Making judgments based on criteria and standards through } \\
\text { checking and critiquing." }\end{array}$ \\
\hline Analysis & $\begin{array}{l}\text { Analyzing } \\
\text { "Breaking materials and concepts into parts, determining how } \\
\text { parts relate to one another.., or to an overall structure or } \\
\text { purpose." }\end{array}$ \\
\hline Application & $\begin{array}{l}\text { Applying } \\
\text { "Carrying out or using a procedure. Applying relates to } \\
\text { situations where learned material is used through products.. } \\
\text {.like presentations." }\end{array}$ \\
\hline Comprehension & $\begin{array}{l}\text { Understanding } \\
\text { "Activities like interpreting, exemplifying, classifying.." }\end{array}$ \\
\hline Knowledge & $\begin{array}{l}\text { Remembering } \\
\text { "Memory is used to produce definitions, facts or lists" }\end{array}$ \\
\hline
\end{tabular}

\section{Methodology}

\section{Summary}

85 students enrolled in the "Special Topics: Art History" course at Kwansei Gakuin University in the 2017 Spring semester. These students were in their second year at university, all came from a Japanese speaking background. The students' ages ranged from 19 to 21 . Of these, 75 completed a 12 item questionnaire on their view of the difficulty of certain types of quiz questions, these questions being based upon verb descriptors common in cognitive domain taxonomies. Students were asked to rank each of the items in terms of difficulty. The quiz was attempted immediately prior to the questionnaire, but students were not aware of their quiz results when surveyed. The students come from three classes, each class with nominally 30 students enrolled, and took the questionnaire at 9 AM, 10:30 AM and 12:40 PM. Due to considerations of anonymity, the data collected from the questionnaire has not been cross-referenced with the scores of the quiz, as the scores contained student biographical information, and as such, only the data on the perceived difficulty was assessed in this study.

The quiz items themselves were developed from an application of Benjamin Bloom's Taxonomy of the Cognitive Domain (1956), and Anderson and Krathwohl's updated version of this taxonomy (2001), which suggests certain verbs for developing questions to develop and assess abilities of 
each of the 6 sets of the taxonomy of the cognitive domain. By comparing the results of student perceived difficulties to the prescribed difficulties inherent in the taxonomy, the researcher was able to make conclusions as to how well the taxonomy has been applied to item development, and may be able to speculate on which areas of cognitive development are lacking support throughout the course. This, in concert with item analysis of student results (although outside the scope of this study), may also give the researcher and curriculum developers a greater understanding of which areas within the cognitive domain students are most comfortable with, and could be a powerful tool of curriculum and syllabus assessment in a longitudinal sense.

To reduce intervening variables in the researcher's application of the verbs to the questions, the quiz contained 12 items repeating the pertinent verbs in two sets of six questions. This allowed for slightly more flexibility in application of verbs to questions, and controlled for intervening disparities in students' understandings of the wordings of the questions. The final data, showing student perception of the difficulties, has therefore been divided into two sets of results, and the differences between the average scores of these results allows us to discern which items were weaker or stronger in their relationship to their intended application. That is to say, it may show which items were well written or poorly written. In addition, by comparing standard deviation of the two sets, item by item, the researcher is able to make conclusions about which items were well or poorly applied by looking at the width of variation between items in set A and B.

\section{Questionnaire}

Below, in figure 4, is a sample of the questionnaire. As noted in the methodology section of this paper, there are two questions relating to each strata of the taxonomy. They are in order in this example, from easiest to most complex, but were randomized in the actual application. All question types had appeared in the syllabus in various activities. In some cases, model answers and explicit instructions for how to answer these types of questions were also offered to students. An example of the questionnaire itself can be seen in appendix 1.

The bars in the chart show the mean rankings for which questions the students thought most difficult. The lower order descriptors are on the left, the higher on the right. Therefore, the taxonomy would suggest that if "perfect" the bars should increase linearly from left to right. In this way, set one matches quite well with the taxonomy, excluding question 4, which is ranked as easier than it should be. 
Fig. 4. Questionnaire Sample

1. What period is this artwork from? (Knowledge)

2. Can you describe the palette? (Knowledge)

3. What is the setting of this painting? (Comprehension)

4. What is the subject of this painting? (Comprehension)

5. What questions would you ask of Malevich? (Application)

6. Can you write a set of instructions on how to make this artwork? (Application)

7. Can you compare this artwork to the artwork you presented in Exhibition 1? (Analysis)

8. How do you know this artwork is from this period, and not a different period? (Analysis)

9. How would Malevich's painting be different if he were painting today? (Synthesis)

10. How would Malevich paint a portrait of your family? (Synthesis)

11. Do you believe this artwork is successful? Why? (Evaluation)

12. Why do you think Malevich is so famous? (Evaluation)

Results

Chart 1. Set 1. Results.

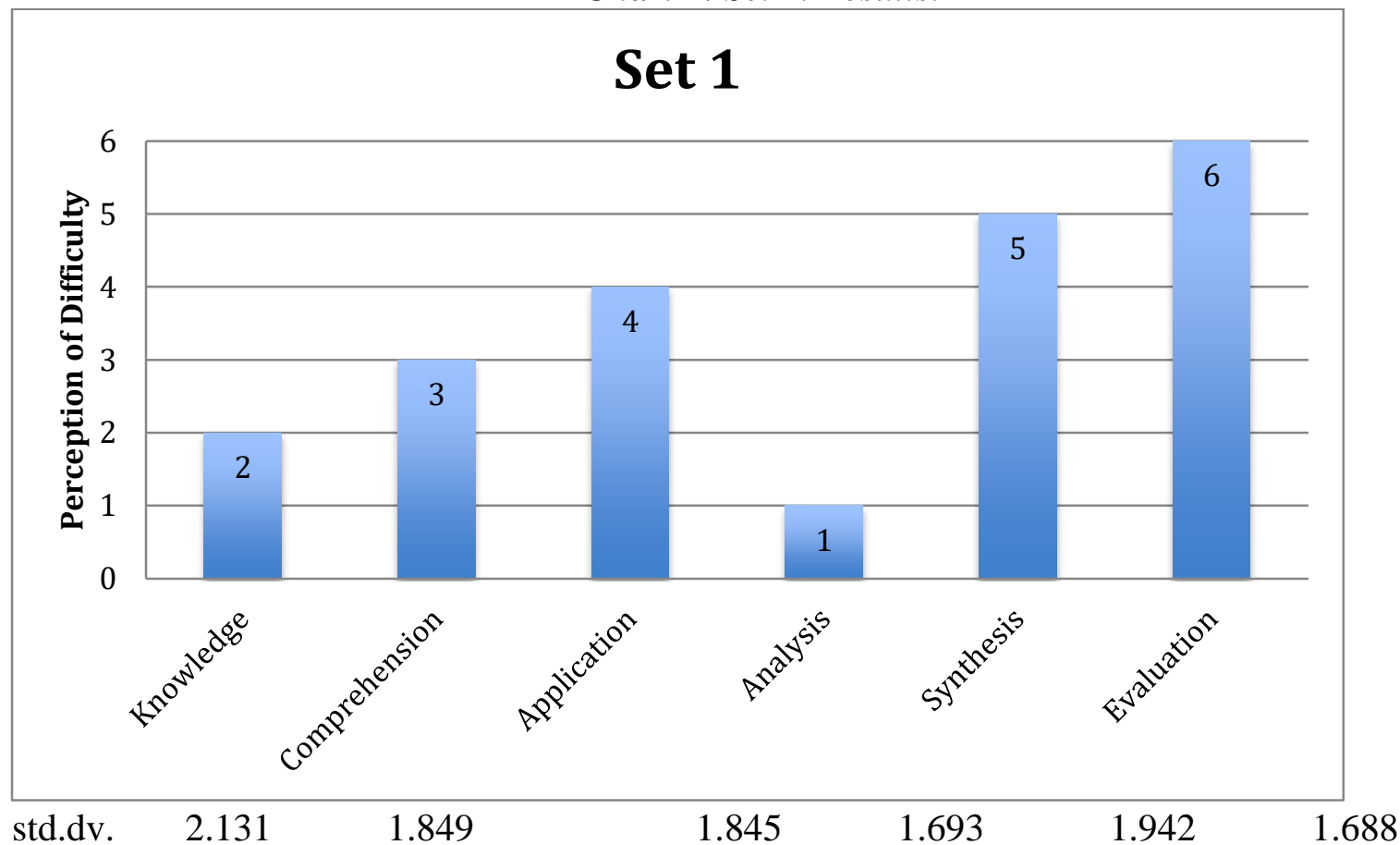


Question 4 is from the "Analysis" descriptor, and the question itself was "Can you compare this artwork to the one you presented in the exhibition?"- the exhibition being a presentation-style activity that students had attempted a few weeks prior to the questionnaire. One possibility is that students are familiar with this question style, and hence find it less difficult: students had encountered questions like this recently in the course. Additionally, there is the possibility that students have encountered questions of this type elsewhere in their studies, or have a good prior knowledge of this type of question and the cognitive work it requires. Another possibility is that wording of the question is problematic. Questions starting with the word "Can", could suggest to students that the correct answer would be a simple yes or no. In this manner it is easier to understand why a student would find this question very easy to answer.

The standard deviation for question 4 is also the lowest in this set. This suggests that as a group students were very sure that this was the question they found easiest. In fact, the standard deviation doesn't very much between questions, sitting at about 1.8 suggesting that as a group there is some consensus. This is relieving, as it suggests, at least for this set, that students understand the objectives and the language of the survey, although it would be better if the deviation was a little lower. The deviation for knowledge sits a little high, suggesting there may be an issue in how this question is understood or dealt with.

Chart 2. Set 2 Results.

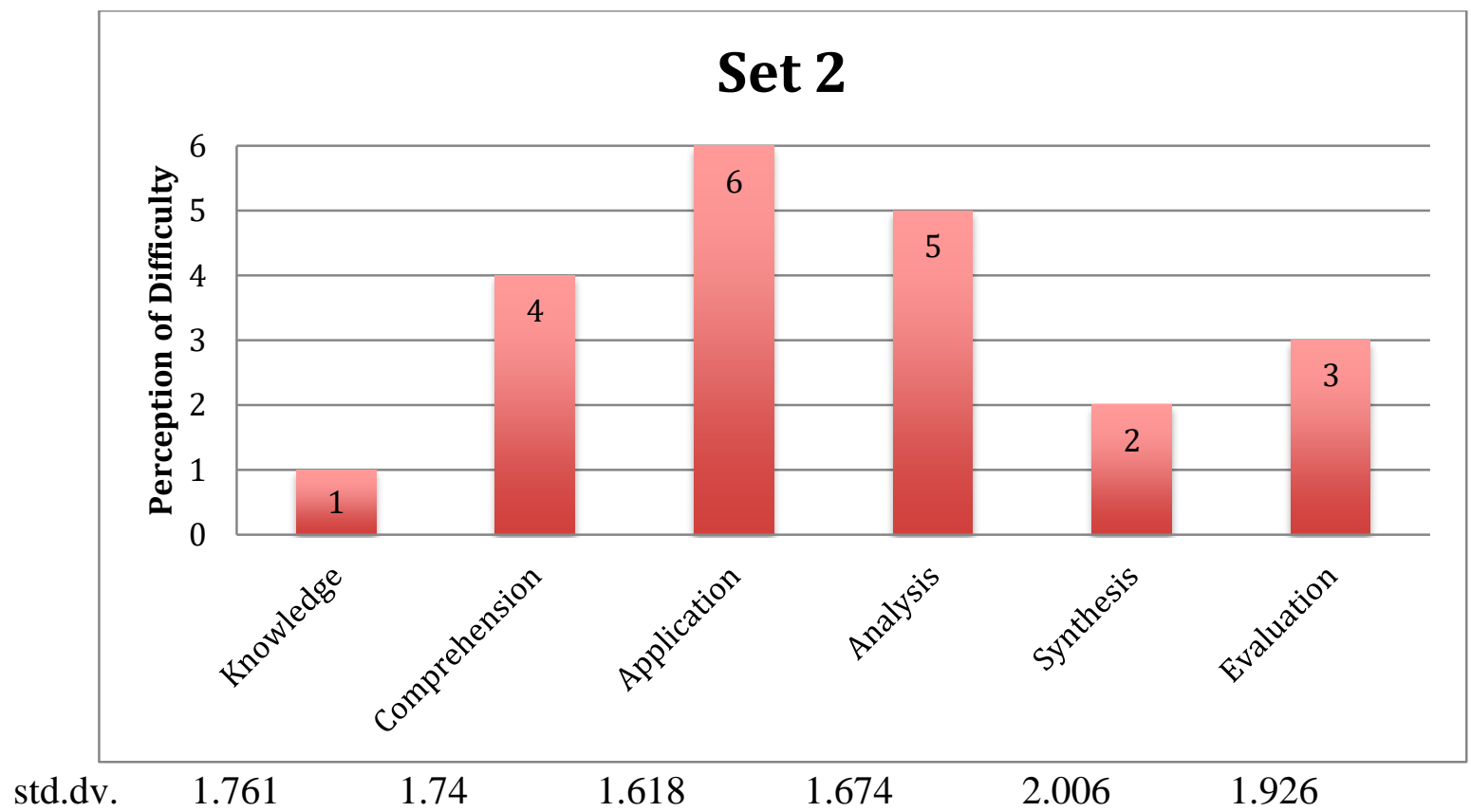

The above chart shows the second set, which indicates much more discrepancy between the student perceptions of difficulty and what the taxonomy suggests. This raises many questions.

Knowledge, the lowest order descriptor is correctly positioned at 1, but the variance with other scores suggests that something is intervening. The upper two descriptors, Synthesis and Evaluation are scored as being easy, which could be attributed to effectiveness of their treatment 
in class, but are more likely related to flaws in the design of the questions or at some point in the methodology of the experiment. This is further confirmed by the discrepancy not being apparent in the earlier set. Again, the standard deviations are written below the chart, the average of which is just under 1.8 This is quite similar to the set 1 average, suggesting that students have the same level of discrepancy amongst themselves for which questions they believe are more difficult. Again, this unfortunately suggests that there is something erroneous in the questions or application of set 2, and does not suggest it is related to problems with how the cognitive domain subsets are addressed elsewhere in the course.

Of note, in set 1 , bar number 4 was seen as the easiest, but in set two it is seen as second most difficult. Again, its standard deviation is one of the lowest. In the second set, this question was "How do you know this artwork is from one period and not another?". The set one question also asked students to work with comparisons in the Analysis descriptor. One possible reason for this discrepancy cold be, the set 1 questions begins with "Can you compare.." directly asking for a comparison, indicating clearly how students approach the question. Whereas the set 2 question beginning with "How do you know..", doesn't give students a clear method for answering it, perhaps forcing them to decide upon the methods for solving it by themselves. In this case, a possible reason for the discrepancy could be the phrasing and verb choice in the question. An additional reason could be that set 1 is asking students to compare works, where set 2 is asking them to compare periods, an arguably more difficult task.

\section{Speculations and Recommendations}

Although the results could be viewed as inconclusive, they still give useful data points to assist in better development of the course. However, it is important to look at some possible faults in the study.

The survey assumed that there is equal and linear progression of difficulty when moving up the taxonomic ladder. Perhaps this is not the case, for example, perhaps some of the subsets are easier to achieve than others, once the requisite subsets below have been attained. Or, perhaps when a student has attained a certain level of competency in a subset, their perception of difficulty is reduced. For example, a student sees Memorization, a lower subset, as being particularly tedious due to the nature of the subset itself, whereas comparison, a part of the analysis descriptor, is more intrinsically fun to perform.

Another limitation to better controlling the input of cognitive domain objectives could include the following: there could be intervening factors such as student engagement or interest in certain topics. For example, students may enjoy some themes more than others, affecting their engagement with the lessons and assessment. In the recent iteration of the course, the Impressionism theme was well liked, and perhaps this had an effect on attainment. This may be an interesting factor to consider when doing a similar study in the future.

A further intervening factor could student prior attainment of skills. Due to this, it is suggests that similar studies attempt to receive data at an early and late point in the course, to give more diagnostic information for development, as well as to allow comparison with with final attainment. 
Research including an item analysis of student performance on the questions themselves would be an appropriate method to gain more insight on this issue.

\section{References}

Anderson, L.W. and Krathwohl, D (eds.) (2001). A Taxonomy for Learning, Teaching and Assessing: a Revision of Bloom's Educational Objectives. Longman. New York.

Bloom, B.S. (1956). Taxonomy of Educational Objectives, Handbook $i$ : the Cognitive Domain. New York: David McKay Co Inc.

Cook, G. (2010) Translation in Language Teaching. Oxford: Oxford University Press.

Coyle, D., Hood, P., \& Marsh, D. (2010). CLIL: Content and Language Integrated Learning. Cambridge, UK: Cambridge University Press.

IBO.org (2016) The IB Celebrates Growth in Asia Pacific. Retrieved from https://www.ibo.org/news/news-about-ib-schools/the-ib-celebrates-growth-in-asia-pacific/

McNamara, S. (2018) Aligning Content to Cognitive Taxonomies: Art History Syllabus Design. Journal of Policy Studies. No. 56. 55-61

MEXT (2014) English Education Reform Plan corresponding to Globalization. Retrieved from http://www.mext.go.jp/en/news/topics/detail/_icsFiles/afieldfile/2014/01/23/1343591_1.pdf

MEXT (ND) Global 30 Project -Establishing University Network for Internationalization, Retrieved from http://www.mext.go.jp/en/policy/education/highered/title02/detail02/sdetail02/1373894.htm

Osaka City. (ND). 大阪市立水都国際中学校 ·高等学校. Retrieved from http://osaka-city-ib.jp/

Saito, Y. (2012) Translation in English Language Teaching in Japan. Komaba Journal of English Education. Vol.3, 2012:27-36

Wilson, L.O. (2001) Anderson and Krathwohl-Bloom's Taxonomy Revised. Originally published in ED 721 (2001), revised 2013. Retrieved from https://thesecondprinciple.com/teaching-essentials/beyond-bloom-cognitive-taxonomy-revised/ 


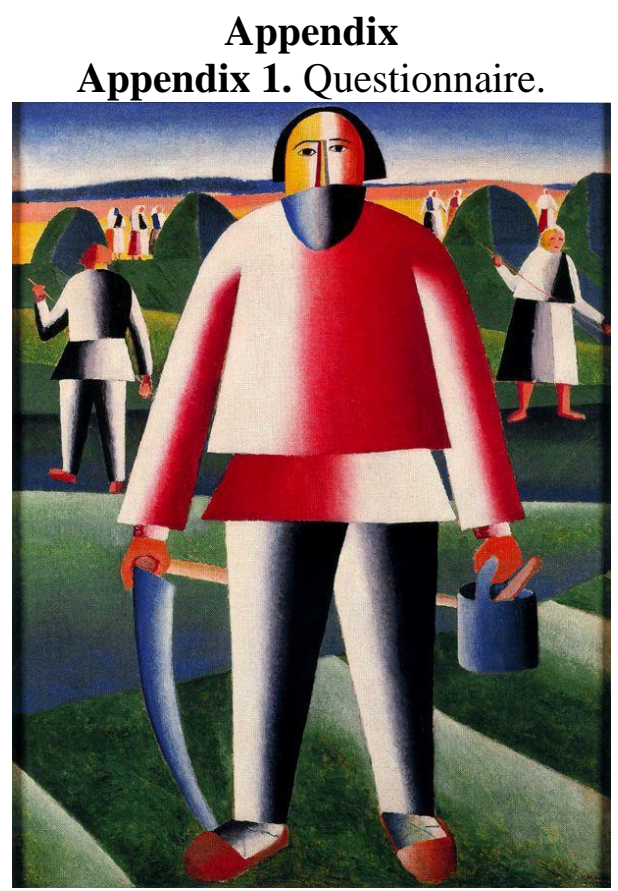

A: Kazemir Malevich, Peasant Woman with Buckets, 1913

Try to answer these questions, and then decide if the question is easy or difficult.

Use any number between 1 and 6 . $\quad 1=$ easy $6=$ difficult.

1. What period is this artwork from?

2. Can you describe the palette?

3. What is the setting of this painting?

4. What is the subject of this painting?

5. What questions would you ask of Malevich?

6. Can you write a set of instructions on how to make this artwork?

7. Can you compare this artwork to the artwork you presented in Exhibition 1?

8. How do you know this artwork is from this period, and not a different period?

9. How would Malevich's painting be different if he were painting today?

10. How would Malevich paint a portrait of your family?

11. Do you believe this artwork is successful? Why?

12. Why do you think Malevich is so famous? 